\title{
“EXCLUSÃO SOCIAL" E CONTROLE SOCIAL: ESTRATÉGIAS CONTEMPORÂNEAS DE REDUÇÃO DA SUJEITICIDADE
}

\author{
José Rogério Lopes \\ Universidade do Vale do Rio dos Sinos
}

\begin{abstract}
RESUMO: Os processos de "exclusão social" compõem um conjunto de referências configuradas historicamente na dinâmica de internacionalização da economia, de orientação neoliberal. Esses processos têm sido estudados e expostos de forma difusa no âmbito das ciências sociais, sobretudo pelas análises econômicas e das políticas sociais, o que reduz o potencial heurístico e interdisciplinar de reflexão sobre o problema. Busco aqui realizar uma reflexão que resgate esse potencial, estruturada na concepção de que a "exclusão social" produz uma nova forma de controle social, reduzindo a potencialidade da sujeiticidade, como definida desde o projeto iluminista, em proveito da supremacia de um modelo de ocidentalização difundido historicamente no desenvolvimento do capitalismo.
\end{abstract}

PALAVRAS-CHAVE: "exclusão social”; controle social; pobreza; autonomia; solidariedade.

\section{"SOCIAL EXCLUSION" AND SOCIAL CONTROL: CONTEMPORARY STRATEGIES FOR REDUCING SUBJECTNESS}

ABSTRACT: "Social exclusion" processes establish a range of historically determined references within the economic internationalization under neoliberal orientation. These processes have been studied and presented in a diffuse way by Social Science and, above all, by economic analyses and policies. This approach, however, reduces the heuristic and the interdisciplinary potential to discuss the question. My purpose here is to stimulate debate on how to rescue this potential, based on the conception that "social exclusion" makes a new form of social control and reduces the potential for subjectness, on behalf of the supremacy of the Westernizing model historically imposed by capitalism development.

KEYWORDS: "social exclusion”; social control; poverty; autonomy; solidarity.

A natureza do trabalho possível de ser exercido na economia global é essencial ao entendimento da questão da exclusão (Dupas, 1999, p.34).

Hoje, na medida em que a sociedade contemporânea afasta-se cada vez mais dos ideais e referências do Estado de Bem-Estar Social, contexto no qual o controle social era exercido na perspectiva da configuração de um Estado totalizante ${ }^{1}$ (Marcuse, 1967), emerge um conjunto de novos condicionamentos sociais que tendem a subsumir as formas de controle social em novas formas de sociabilidade.

Entre as formas emergentes de sociabilidade, aquelas que se enformam no quadro das ações e relações que se costumou denominar de "exclusão social" são importantes para análise, seja por sua multidimensionalidade ou por sua complexidade causal.

De fato, a concepção de "exclusão social" costuma ser relacionada a um plano de causalidade complexo e multidimensional, diferenciando-se da concepção de pobreza, sobretudo porque aquela é uma condição produzida na emergência do neoliberalismo, caracterizada pela estratégia de sobredeterminação constante dos termos que fundam e reproduzem os jogos contemporâneos entre mercado, trabalho, Estados, poder e desejos.

Enquanto a pobreza é um desdobramento das relações históricas e estruturais de oposição entre os interesses de classes, portanto, um fenômeno econômico que se configura na questão social derivada das relações capital x trabalho, a "exclusão social" se caracteriza por um conjunto de fenômenos que se configuram no campo alargado das relações sociais contemporâneas: o desemprego estrutural, a precarização do trabalho, a desqualificação social, a desagregação identitária, a desumanização do outro, a anulação da alteridade, a população de rua, a fome, a violência, a falta de acesso a bens e serviços, à segurança, à justiça e à cidadania, entre outras.

As condições que configuram a pobreza confirmam a dimensão de sujeito do pobre na razão do controle de sua participação na economia, uma vez que a gênese do capitalismo pôs em evidência a produção de uma pobreza em massa, de forma mais homogênea do que a pobreza que se produziu no desenvolvimento do capitalismo, em finais do século XIX até meados do século $X X$. Dessa forma, pode-se afirmar que a pobreza foi um elemento importante para a acumulação primitiva do capital e para a manutenção dos níveis de exploração do salário, no início do capitalismo: a fase da superexploração do trabalho, descrita por diversos autores, de Marx (1984) a Dobb (1983). Entretanto, o desenvolvimento das relações produtivas, no capitalismo, envolveu essa massa de pobres em uma estrutura dinâmica de condições e fatores diversos, que impôs aos sujeitos a criação e 
efetivação de estratégias de sobrevivência distintas, que começaram a se diferenciar na medida em que:

1. "esses fatores afetam os indivíduos de formas diferentes de acordo com sua inserção na sociedade; seu efeito dependerá da posição de cada indivíduo em termos de relações de produção" (Dupas, 1999, p.28); ${ }^{2}$

2. sua consciência de classe definiu orientações distintas de agregação ou articulação em torno de organizações de defesa de seus interesses ou de reinvindicação pela satisfação de suas necessidades.

Nesse sentido, a própria experiência decorrente dos movimentos de reivindicação das classes trabalhadoras, que se especializaram em níveis locais, regionais e nacionais, ao invés de se internacionalizarem, permite afirmar que, hoje, "grupos que partilham a mesma pobreza chegaram lá de diferentes maneiras e têm diferentes probabilidades de saírem dela" (Dupas, 1999, p.29).

Essa idéia pressupõe, também, que a pobreza produz lugares, como contextos onde ocorrem formas distintas de organização dos sujeitos que participam dos diferentes modos de produção. Na visão de M. Santos (1997), os sujeitos caracterizam-se como atores sociais na medida em que são reconhecidos como elementos presentes na configuração das estruturas ${ }^{3}$ que interagem para a constituição da realidade social. Evidente que essa presença interagia, e ainda interage como força, na constituição dos mecanismos de controle social.

A própria lógica de constituição dos direitos que enformam o ideal de cidadania, nas sociedades ocidentais, seguiu esses condicionamentos (Lopes, 2001), de forma que a sua universalização tornou-se mais um problema que uma solução. Ou seja, como tais direitos foram se institucionalizando na medida em que as reivindicações das classes trabalhadoras foram se diversificando e se localizando, no desenvolvimento do jogo de forças entre elas e o capital, estabeleceu-se uma gradação no acesso a tais direitos, que resultou em uma hierarquia dos sujeitos assistidos pelos mesmos. Essa hierarquia estaria na base mesma da distinção que Rosanvallon (1995) elabora entre droits-libertés e droits-créances (direitos libertados e direitos créditos, que pressupõem a liberdade política e a condição da redistribuição das riquezas). E aqui surge uma hipótese de trabalho, um tanto polêmica: a de que a hierarquia dos assistidos pelos direitos de cidadania corresponde a uma estratificação das condições de inserção dos trabalhadores no mercado, que hoje se explicita em uma disputa pela permanência no próprio mercado, como uma das novas formas de controle social.

Se antes a condição de inserção no mercado condicionava a configuração dos lugares próprios dos sujeitos, hoje o próprio mercado tornou-se o lugar dos sujeitos.
A importância dessa formulação está assentada na necessidade de perceber que o ideal de igualdade que se produz e reproduz no quadro do desenvolvimento de tais relações, nas sociedades ocidentais, desdobra-se da determinação reconhecida na e pela igualdade do trabalho. Ora, se tal hipótese se confirmar, há duas questões daí derivadas que merecem nossa atenção: uma refere-se ao potencial de autonomia do sujeito contemporâneo, sobretudo daquele que trabalha, ou procura trabalho; outra se refere ao reconhecimento dos tipos e graus de solidariedade que os sujeitos são capazes de estabelecer nas suas relações em sociedade.

Esse contexto, sucintamente configurado, permite, por sua vez, que se estabeleça um paralelo entre a gênese e o desenvolvimento da pobreza, com a gênese e o desenvolvimento daquilo que ainda denominamos de sociedade. Segundo Dubet (1996), a sociedade pode ser caracterizada por cinco critérios, quais sejam: ela é moderna, é sistêmica, é um Estado-Nação, é industrial e os atores sociais são institucionais.

A medida desses critérios explicita uma orientação fundamental para essa análise. Na razão pela qual expõe tais critérios, Dubet (1996) assim os justifica:

- a sociedade é moderna e a sociologia é evolucionista, pois estuda e explica "a história da humanidade como um processo que vai da tradição do primitivo das tribos para o moderno, para a divisão do trabalho" (p. 2) (a tradição da modernidade);

- a sociedade é sistêmica, não porque toda ela seja sistêmica, ${ }^{4}$ e sim, porque explicar a vida social tem implicado em explicar para quê as coisas servem no interior do sistema, segundo as relações funcionais que os diversos elementos mantêm, nas sociedades complexas;

- a sociedadeé um Estado nacional, porque ela se "encarna em uma forma particular que é o Estado Nação”, em uma "integração funcional sistêmica de uma economia nacional, de uma cultura nacional e de um sistema político nacional"(p.3), quer seja ela pensada como efetivada pela burguesia, pelo Estado ou pela cultura;

- a sociedade é industrial, o que pressupõe reconhecer e explicar os conflitos de classes que dominam na sociedade. Esse reconhecimento assume pelo menos duas formas teóricas gerais: primeira, a de que a integração social não pode ocorrer sob a lógica de tais conflitos, pois eles opõem antagonicamente as classes sociais; segunda, a de que "o conflito de classes reforça a integração social porque se trata de um conflito negociável" (p.4) sob o manto da democracia; ${ }^{5}$

- na sociedade, o ator é o sistema, ou seja, "o ator social é definido como a vertente subjetiva do sistema. Meus sentimentos amorosos, minhas opiniões políticas, minha maneira de vestir, são o produto da minha 
socialização, isto é, a maneira como eu me integrei subjetivamente nos objetivos do sistema" (p.4). E aqui, devo lembrar Weber (s/d), quando afirma, complementarmente, que o sistema é produzido pelos atores. Dessa complementaridade, pode-se afirmar que a ordem social "se explica pela ação social socializada” (Dubet, 1996, p.4).

Eu incluiria uma sexta categoria, que tem a ver com a dinâmica de formação e desenvolvimento da sociedade, estruturada no fato de que a sociedade é institucionalizada (uma contribuição antropológica sobre o processo de socialização). Ou seja, a institucionalização implica reconhecer que não só o ator é o sistema, mas que a modernidade, a industrialização e a formação do EstadoNação se reproduzem institucionalmente. A importância desse sexto critério está fundamentada na concepção de que a instituição tem historicidade e autoridade moral (Berger \& Berger, 1977) e que é ela que promove a reflexividade da vida moderna, segundo Giddens (1991).

A maneira como esses critérios imbricaram-se, na produção da sociedade, implicou em um movimento constante e dinâmico da figura do sujeito, da categoria de pobreza, das condições de trabalho e dos modelos de integração social (além, é lógico, das próprias idéias de Estado e de mercado).

De uma forma geral, pode-se identificar uma variação de combinações assimétricas desses elementos, conforme foram se organizando nas diversas sociedades concretamente estabelecidas, segundo os critérios anteriormente definidos. Essa diversidade implica que comete um equívoco aquele que pretende explicar as condições atuais pela presença e papel dos atores sociais fundantes dessa relação, quais sejam, a burguesia, os trabalhadores e o Estado (sendo que a pobreza desdobrar-se-ia como uma das condições da segunda categoria de atores).

Ora, o desenvolvimento da sociedade mostra que algumas dessas figuras tornaram-se difusas, chegando a quase se tornarem anônimas nesse processo. ${ }^{6}$ Isso decorreu sobretudo devido a dois fatores interligados: a sociedade manteve-se sistêmica e, mais que isso até, ampliou a cobertura do mundo sistêmico sobre o mundo vivido; por outro lado, a economia, antes um componente funcional da integração promovida pelo estado nacional, tornou-se o próprio modelo de integração, na medida em que se internacionalizou.

Daí, as dificuldades das políticas sociais e a diversidade de programas públicos de combate à pobreza ou à exclusão, que se mantiveram locais e localizadas.

A internacionalização da economia foi uma sobredeterminação do componente-meio para um componentefim, que rompeu não só com a configuração e a soberania do Estado-Nação, mas tem rompido também com a idéia de sociedade. Nesse sentido, rompeu também com a idéia de sujeito (como ator social), na medida em que transformou a razão ou a racionalidade que sustentava os vínculos entre os atores sociais e configurava a esfera pública, definidos desde o projeto iluminista (Kant, 1992). ${ }^{7} \mathrm{Na}$ raiz dessa transformação é que emergem as concepções de exclusão social.

\section{Exclusão Social: Caminhos e Perspectivas}

A concepção de exclusão aparece de e com diversas formas. Pode-se pensar seu aparecimento segundo modelos distintos de análise, conforme o locus ou o focus das abordagens de alguns autores. Assim, ao debruçar-se sobre a literatura, o leitor encontra referências importantes nas obras de Kliksberg (1993), Rosanvallon (1995), Rogers, Gore e Figueiredo (1995), Santos (1995), Bourdieu (1997), Atkinson (1998), Castel (1999), Paugam (1999), Sen (2000) e Touraine (2000), entre alguns estrangeiros, e, entre os autores nacionais, Kowarick (1979, 1991, 1994), Foracchi (1982), Santos (1987), Nascimento (1994), Sposati (1996), Martins (1997), Oliveira (1997), Luis E. Wanderley (1997a), Veras (1999), Wanderley (1997b), Zarth (1998) e Dupas (1999).

Do grupo de estrangeiros, destaco os trabalhos de Atkinson (1998) e de Rogers et al. (1995), essenciais para a compreensão da emergência da concepção de exclusão social. $\mathrm{O}$ primeiro explicita o caráter dinâmico e a natureza multidimensional da exclusão social, além da extensão desse processo a campos sociais mais amplos que a participação na vida do trabalho. O segundo, uma coletânea organizada pelos autores, circunscreve a gênese da exclusão social em fenômenos concretos ocorridos na Europa, desde finais da década de 1970 (como o aumento da pobreza urbana, a falta de perspectiva e a insegurança causadas pelo desemprego entre jovens e adultos, a falta de acesso a emprego ou renda nas minorias étnicas e entre imigrantes), fenômenos esses relacionados à internacionalização da economia e à revolução tecnológica, além de confirmar sua natureza multidimensional, analisar parte da literatura existente e enumerar categorias de excluídos, nas diversas sociedades. ${ }^{8}$

Um ponto de convergência entre essas obras é o do contexto nacional de importância das reflexões sobre os processos de exclusão social, que coincidem em torno da bibliografia francesa sobre o assunto. Essa localização está assentada no descompasso enfatizado entre os processos de modernização e os processos de "globalização" que afetam as sociedades nacionais.

Em minha abordagem, a ênfase em uma bibliografia francesa tem a ver com tal descompasso, na medida em que ela permite pensar que a preocupação da teoria social francesa está assentada em discutir as transformações na formação e no desenvolvimento do Estado-Nação. Daí que, em princípio, pode-se pensar a questão da 
exclusão a partir da nacionalidade de algumas reflexões sobre a modernidade.

$\mathrm{Na}$ França, a formação do Estado-Nação e seus pressupostos territoriais e de cidadania; na Inglaterra, a gênese e o desenvolvimento do capitalismo, com a ênfase na modernidade, cuja entrada tardia da Reforma não configura uma sociedade de base religiosa; nos EUA, uma formação plural, com ênfase na dinâmica institucional, que impede o desenvolvimento de uma concepção de Estado-Nação como o francês, prevalecendo o princípio da sociedade civil organizada em torno de ações cívicas (Tocquevile, citado em Pedlowski, 2001), que configuram um estilo de vida (a difusão do American Way of Life). A própria configuração da democracia, na contemporaneidade, está mais assentada nessa referência americana do que na francesa, como o demonstraram os argumentos da invasão do Iraque e seus desdobramentos.

No caso francês, predomina a perspectiva da autonomia definida no campo das ações de cidadania; no caso inglês, a perspectiva do mercado como agente do desenvolvimento e, no caso americano, a instituição como ator social.

Quais são as implicações dessa configuração?

A primeira diz respeito à herança que recebemos na sociedade brasileira, que fundiu os modelos de reflexão sobre tais perspectivas, gerando uma tensão no campo teórico, marcado pela inserção periférica nesse debate. Ou seja, aquilo que hoje justificamos como um campo plural de reflexões é um pano de fundo para justificar nossas próprias indecisões sobre os rumos que devemos tomar. A segunda diz respeito a essa própria indecisão, na medida em que ela obnubila uma teleologia acerca da ação do sujeito, na contemporaneidade, colocandonos em um labirinto.

A história de nossa organização local das variáveis que movimentam as relações desiguais, no desenvolvimento do capitalismo, assim como os sistemas explicativos que fomos elaborando para apreender esse desenvolvimento, dão conta de explicitar nossa condição. As consequiências do modelo de desenvolvimento capitalista em nossa sociedade produziram categorias de pensamento configuradas diacronicamente pelos fenômenos de marginalização (de influências marcadamente modernizadoras e econômicas), de espoliação (de influências marcadamente territoriais) e de segregação (de influências geradas em uma tríplice dimensão: de classes, de raça-etnia e de relações de gênero) (Veras, 1999; Wanderley, 1997a).

Dessa maneira, na medida em que avaliamos nossa inserção periférica no desenvolvimento da concretude dessas relações e no debate teórico acerca delas, redesenhamos a história da exclusão social no ocidente. O desconhecimento desse processo pode acabar por confundir o real com o conceito, a concretude com a abstração. Ou seja, podemos confundir a escala de percepção dos problemas com a escala de sua resolução (Santos, 1997).

A importância do debate brasileiro acerca dos processos de exclusão hoje em voga, considerando a história e as mudanças havidas no desenvolvimento da questão social e das relações de desigualdade (Wanderley, 1997), permite afirmar que, se as condições que configuram a pobreza confirmam a dimensão de sujeito do pobre na razão do controle de sua participação na economia, na "exclusão social" produzida no mundo neoliberal, mais que controlar ou negar o acesso ao trabalho ou ao consumo, controla e nega-se a própria condição de "sujeiticidade (o que faz o ser humano ser sujeito $^{9}$ ) do indivíduo” (Sung, 2002, p.19).

Esta transformação qualitativa dos pressupostos antes identificados com os problemas decorrentes da desigualdade sócio-econômica (a exploração, a marginalização, a pobreza) permite entrever que a injustiça primordial não é mais exclusivamente sócio-econômica ou material, mas também simbólica. Os problemas decorrentes dessa injustiça simbólica caracterizam-se, segundo Honneth, pela "hostilidade, a invisibilidade social e o desrespeito que a associação de interpretações ou estereótipos sociais reproduzem na vida cotidiana ou institucional. Este tipo de comportamento implica no prejuízo da auto-estima de indivíduos e grupos, mediante processos intersubjetivos" (Souza, 2000, p. 157). Assim, está em jogo, hoje, a relação entre fatores econômicos e fatores nãoeconômicos na produção da vida social (Touraine, 2000).

A mundialização dos mercados, que é encoberta pela ideologia da globalização, gerou a exclusão daqueles que não participam do jogo promovido e estruturado na idéia de que quanto menos controle, melhor, ou de que não há o que fazer frente à globalização, como fato inexorável.

Em países desenvolvidos, essa população está entre 13 a 15\%. Em países emergentes, como Brasil e México, está em torno de $50 \%$. Em países subdesenvolvidos, como os africanos ou andinos, está entre 80 a $90 \%$ (Touraine, 2000).

A crescente apartação social imposta a essas populações produz uma situação que obriga a pensar as relações entre desinternacionalização x redemocratização x jogo ideológico.

Entretanto, essas relações costumam ser recortadas e analisadas parceladamente, conforme a matriz do campo de saber que se debruça sobre os fenômenos denominados de "exclusão social". Do ponto de vista econômico, a justificativa estrutura-se na garantia de acesso ao bem comum. Do ponto de vista das análises em políticas sociais (sobretudo nas áreas dos estudos em educação, saúde e assistência social), a justificativa atual estrutura-se na defesa da redemocratização, que considera o sentido da alteridade (da diferença) como conquista de democracia.

Em uma rápida retrospectiva histórica, verifica-se que 
a centralidade política assumida ideologicamente pela necessidade da redemocratização, em contextos de produção de desigualdade, não é novidadeira. Nos séculos XVII e XVIII, a questão se colocaria em termos de tirar o poder do rei e passá-lo ao povo. No século XIX, a questão seria a regulação da participação social e da desigualdade na apropriação da riqueza com leis sociais. No momento atual, a questão é como colocar a economia (os meios) a serviço dos fins.

Nesse movimento, a razão da participação autônoma e/ou solidária dos sujeitos na produção da vida social mudou substancialmente. Acima de tudo, essa participação foi condicionada por um gradual parcelamento dos ideais representativos, nas sociedades democráticas, ajustado ao reconhecimento das diferenças culturais, étnicas ou de gênero e às demandas da internacionalização da economia. No seio de tais mudanças, a hegemonia mundial adquiriu novos contornos, conforme foram se formando blocos continentais e intercontinentais de relações econômicas, entre países centrais e periféricos do sistema capitalista, que reforçaram, em níveis locais, a fragmentação dos sistemas produtivos e a competitividade pelos postos de trabalho (fenômeno notado claramente no Brasil).

Ocorre que esse parcelamento não pressupõe a combinação entre o direito à diferença e a participação econômica (Lopes, 2002; Souza, 2000). Essa combinação desdobra-se na necessidade de garantir que o acesso ao bem comum preserve a particularidade de cada um, o que implica, por outro lado, recuperar a capacidade de ação e de sentido dos atores sociais. E essa recuperação transita na contra-mão dos canais de controle social contemporâneos.

Hoje, e cada vez mais, a sociedade é vista como um subproduto da atividade econômica, onde a radicalidade da ação social é excluída pela hegemonia econômica, tecnológica ou militar. Torna-se necessário, então, reencontrar a criatividade e a capacidade de agir.

Para tanto, temos que separar as questões de urgência ou importância dramáticas que afetam as sociedades contemporâneas, para localizar as expressões que estão na base dos novos conflitos sociais (Touraine, 1989), que são morais, são lutas por dignidade humana e reconhecimento (Honneth, 1992).

\section{“Exclusão” x “Inclusão Social”: o difícil cálculo da experiência social, ou como realizar os registros da solidariedade social}

A antropologia, de certa forma, já anunciava a redução da sujeiticidade na "exclusão social" quando discutia o processo de ocidentalização. Em "Raça e História", LéviStrauss (1976) já indicava que a ocidentalização pressupunha o nivelamento das alteridades culturais sob um duplo aspecto: a preeminência do conceito de raça sobre o de diversidade cultural e a hegemonia da concepção de história cumulativa, como progresso. Aliás, nada é mais coerente com a concepção de história cumulativa do que a ideologia neoliberal de que não há o que fazer, pois estaríamos "presos" à condição globalizada, reféns dos processos de desenvolvimento contemporâneos.

Nesse sentido, a internacionalização da economia é a face estrutural do processo de ocidentalização, que constitui o que Negri (2002) denominou de Império.

E aqui, a ideologia da globalização coloca um elemento importante para análise. Ela se reproduz na escala dos fatores econômicos e não econômicos, enquanto a internacionalização se reproduz na escala dos fatores econômicos. Na medida em que o escopo da globalização é mais amplo que o da internacionalização, coloca-se um hiato entre a experiência efetiva da internacionalização, com seus desdobramentos na vida social, e as conseqüências da globalização.

Um dos aspectos que já se caracterizou nesse hiato é a concepção de fragmentação da experiência social contemporânea, sustentada pela idéia de pós-modernidade. Harvey (1992), ao discutir essa condição pós-moderna, mostrou que se tratava mais de uma estrutura de sensibilidades que se desdobra do processo de compressão do espaço-tempo na vida contemporânea. Esse processo foi produzido pela intensificação dos sistemas de transporte e informação que estão na base das transformações necessárias à internacionalização da economia, sustentadas pelo modelo produtivo de acumulação flexível, que substituiu o fordismo.

Essa idéia está na base de alguns discursos sobre exclusão social, que vêem na ideologia da fragmentação da experiência social um argumento para a necessidade de retotalização dos ordenamentos comunitários e dos condicionamentos culturais, no âmbito do que se configurou denominar de mundialização. O que eu entendo, na análise dessa concepção de fragmentação, é que se trata de uma difusão da urdidura ideológica que não encontra sustentação na análise dos movimentos de internacionalização do capital, ainda estruturados em escalas nada fragmentadas.

Outro aspecto desse hiato, que quero enfatizar aqui, é o descompasso entre o plano das esferas prática e sensível da experiência social (a práxis, para Lefebvre, 1977), elemento forte e ainda pouco explorado nas análises sobre exclusão social.

E aqui, esse descompasso deve ser calculado segundo a perspectiva da ruptura causada pela economia global na concepção de sociedade e nos ideais comunitários da modernidade, que influenciam as políticas sociais de "inclusão".

E, se elaboro aqui uma afirmação que passa pela idéia de cálculo é porque, enquanto as experiências dos sujeitos excluídos remetem a um plano de causalidades 
complexas e multidimensionais - e mesmo a um quadro de relações contemporâneas muito variadas - a centralidade das políticas sociais ainda estrutura-se pelo parâmetro da renda per capita dos sujeitos. Reconhecer essa situação implica afirmar que o cálculo das políticas sociais é econômico, em última instância, ou seja, as políticas sociais são controladas pelas políticas econômicas, são reféns destas.

Os registros teóricos atuais dão conta de analisar algumas consequiências dessa determinação. Trabalhos como os de Rosanvallon (1995), Sen (2000) e Touraine (2000) explicitam, em medidas diferentes, os prejuízos causados pelos processos de exclusão social nos condicionamentos que estruturam a vida coletiva e as políticas sociais contemporâneas. Sobretudo, afetando o escopo de representações, que se formou institucionalmente em torno da grande contradição moderna entre a autonomia e a liberdade, que define o estatuto do sujeito, desdobrado do uso da razão no projeto iluminista (Badiou, 1994).

Rosanvallon (1995) busca superar a idéia de exclusão afirmada como incapacidade de satisfazer as necessidades, para mostrar que ela é um processo, com desdobramentos que afetam profundamente o psiquismo dos indivíduos, que precisarão, de agora em diante, se ressocializar. Ao analisar o escopo da exclusão social em uma perspectiva política, afirma que é necessário requalificar o Estado para garantir o direito dos sujeitos excluídos de viverem em sociedade.

A análise de Rosanvallon (1995) permite considerar o profundo impacto dos processos de exclusão nos indivíduos-sujeitos, ao discutir o caráter dos direitos sociais na contemporaneidade. ${ }^{10}$ Integrar os sujeitos (através do direito de inserção) "coloca em questão um tipo de norma que integra o fato de que os indivíduos se encontram em situações singulares e que eles então devem ser tratados particularmente para que uma verdadeira equidade seja realizada". Não se trata mais de pensar as ações do Estado segundo uma teoria da dívida social produzida nas relações capital $\mathrm{x}$ trabalho (que, segundo o autor, produz direitos passivos, uma relação de dependência e sujeitos subordinados), mas sim, de buscar "a via de uma implicação recíproca do indivíduo com a sociedade", que restabeleça um imperativo cívico de participação dos sujeitos.

Seu cálculo pode ser resumido grosseiramente na seguinte situação: o Estado equaciona as oportunidades de inserção dos sujeitos, considerados em suas singularidades, mas assegura aos mesmos uma Renda Mínima de Inserção (RMI), que lhes permita sentirem-se seguros. Entretanto, esse direito seria inseparável de certas obrigações dos indivíduos para com a sociedade, que canalizariam a possibilidade deles participarem de um movimento de ressocialização. Observe-se o deslocamento das mediações que efetivam o controle social nessa perspectiva.
O princípio que ordenaria as implicações recíprocas entre indivíduo e sociedade é o resgate de uma solidariedade de base orgânica-cívica, na conformação do corpo social. Tratar-se-ia de uma nova figura dos direitos, que pretende responder à demanda crescente por autonomia entre os sujeitos, sem "vampirizar" um Estado Providência (cujo custo é infinanciável hoje), ou recair em políticas assistencialistas.

A proposta do RMI, dessa forma, buscaria articular ajuda econômica e participação social, proporcionando uma segurança-liberdade de ação (direito de integração, ou de inserção), assentada em obrigações (dever de implicação-participação), segundo as singularidades de cada indivíduo. Tal cálculo visa ultrapassar "a oposição clássica entre direitos formais e direitos reais denunciada por Marx, tentando dar substância a um princípio de eqüidade que não seja mecanicamente voltado para o da igualdade".

O caráter moral desse "novo" direito é evidente e até enfatizado pelo autor. À substância do direito, é acrescentada uma forma de utilidade social, que pressupõe os indivíduos como cidadãos ativos e participantes de um corpo social solidário.

A diferença entre o princípio de solidariedade do autor e o de Durkheim estaria marcada, segundo Ewald (1995), pelo fato de que a solidariedade orgânica durkheimiana é ditada pelo sentimento do risco, representado socialmente por uma anomia, enquanto a solidariedade orgânicacívica é ditada pelo sentimento de pertencer à mesma comunidade, à mesma nação.

O sentido tradicional de solidariedade desloca-se, assim, dos termos contratuais que o fundavam, para termos nacionais, visando inaugurar uma "seguridade nacional", sustentada por um "Estado-cívico-providência", que substitua a "seguridade social" (Ewald, 1995).

Nos termos dessa proposta, encontramos um deslocamento da figura do sujeito como ator social, do indivíduo para o Estado. A medida da requalificação do Estado seria a da restruturação da própria idéia de sentimento nacional, estruturada por uma "nova" combinação entre solidariedade e civismo.

O problema mais evidente dessa proposta é o seguinte: na medida que o Estado nacionalizasse a nova questão social produzida pelos processos de exclusão, que têm uma causalidade complexa e difusa, originada no desenvolvimento da internacionalização da economia, qual seria o limite de autonomia do próprio Estado? Desdobrando-se dessa problemática, quais seriam as obrigações cobradas dos sujeitos e quais seriam as condições do Estado de sustentar a "pressão positiva" que recairia sobre ele da demanda dos sujeitos por terem seus direitos levados a sério?

O paradoxal na elaboração de Rosanvallon não é o estabelecimento de obrigações aos sujeitos que acessam 
os direitos de inserção - aliás, fato reproduzido em todas as propostas de Renda Mínima efetivadas na década de 1990, no Brasil - mas a consideração, mesmo que implícita, que tais obrigações caracterizam os cidadãos ativos, segundo um princípio de solidariedade cívica, que aparece como elemento apriorístico. ${ }^{11}$

Dessa forma, a contradição moderna entre autonomia e liberdade busca ser superada pela idéia de "civilidade", cuja finalidade é dar nova legitimidade ao Estado (Ewald, 1995).

Ora, porque desloca o campo dos direitos do escopo formado nas relações capital x trabalho, que produziu o chamado Estado-providência, como mediador que efetiva políticas sociais indenizatórias, é que Rosanvallon (1995) supõe que este Estado produz direitos passivos, uma relação de dependência e sujeitos subordinados. $\mathrm{O}$ autor afasta da análise a condição histórica de que os direitos são conquistados em um campo de conflitos entre atores sociais distintos, seja ele qual for, mas sempre marcado pela apropriação dos recursos materiais e simbólicos que visam garantir um ideal de autonomia aos sujeitos, que é sempre configurado pelo momento histórico e exteriorizado na forma de uma ilusão social partilhada pelo conjunto das subjetividades projetadas pelos indivíduos na vida coletiva (Bertrand, 1989).

Mais apropriada seria a concepção de Oliveira (1988, 1998), segundo a qual o campo dos conflitos pela autonomia e liberdade (na forma da moderna luta de classes) deslocou-se da relação capital x trabalho para o campo de lutas pela apropriação do fundo público. Nesse deslocamento, novos direitos foram se configurando, na razão de reivindicações que incidem sobre os investimentos do fundo público em políticas sociais orientadas para novas problemáticas da vida social. É nesse campo que se enforma todo um conjunto de Organizações não-governamentais, com objetivos e áreas diversas de atuação e de representação dos segmentos sociais de sujeitos contemporâneos.

Distintamente do cenário europeu ou americano, no cenário das sociedades periféricas, ou semiperiféricas ao núcleo orgânico do capital internacional (Arrighi, 1997), a sociedade civil não estava organizada para dar sustentação a esses novos direitos, na forma de uma solidariedade cívica. O Estado, nessas condições, teve seu papel modificado pela pressão de setores organizados, com força para reivindicar e apropriar-se do fundo público, reproduzindo, na esfera pública, a estratificação das condições de inserção dos trabalhadores no mercado, que correspondia à hierarquia dos assistidos pelos direitos de cidadania.

Produziu-se, assim, na esfera pública, uma zona de disputas por projetos sociais distintos, que se apropriam dos fundos geridos pelo Estado, que foi um importante apoio à argumentação oficial da necessidade de reformar o próprio Estado, desobrigando-o de alguns deveres contratados com a sociedade. Simultaneamente, na medida em que essas Organizações efetivam projetos financiados pelos fundos públicos, muitas vezes elas acabam tuteladas pelo próprio Estado, reproduzindo funções institucionais no trato com os sujeitos a que se dirigem os projetos (Lopes, 2004).

Assim, novamente a experiência brasileira refaz o desenho da história da exclusão social no ocidente. $\mathrm{O}$ deslocamento do campo de conflitos pela autonomia e liberdade, onde as reivindicações regularmente produzem formas de organização dos sujeitos, mudou o campo institucional de reivindicação dos direitos, enfraquecendo alguns atores sociais tradicionais (como os sindicatos) que necessitam adaptar-se aos novos condicionamentos orientados pelos atores fortalecidos nesse processo.

São características desses novos condicionamentos o conhecimento da burocracia e dos procedimentos legais da rotina do Estado, dos mecanismos de produção do orçamento público, do direito público, da formação de lobbies para atuação nas esferas governamentais, entre outras. A experiência e a formação exigidas para tal atuação criaram mediadores de classe média, ou exigiram uma formação complementar dos mediadores tradicionais, e reduziram as condições para a participação dos sujeitos excluídos.

Uma possível explicação a essa redução da sujeiticidade anuncia-se nas obras de Sen (2000) e Touraine (2000). Sen considera que as discussões sobre a superação da exclusão social, ou da pobreza, devem ser contextualizadas no conjunto das teorizações sobre a idéia de desenvolvimento. Porém, o desenvolvimento não pode ser pensado exclusivamente como "PNB, aumento de rendas pessoais, industrialização, avanço tecnológico ou modernização social" (Sen, 2000, p.17), embora esses sejam aspectos importantes, mas deve ser substancialmente "visto como um processo de expansão das liberdades reais que as pessoas desfrutam" (Sen, 2000, p.17).

Para tanto, as principais fontes de privação de liberdade devem ser removidas, para que as pessoas pobres, hoje, possam incorporar-se no movimento coletivo pela definição de um projeto de desenvolvimento.

Nesse sentido, a liberdade pode ser caracterizada por duas razões: a avaliatória e a da eficácia (aumento de liberdade e a livre condição de agente); tais liberdades permitem compreender o nível de participação dos sujeitos na escolha social e da tomada de decisões públicas que impelem o progresso das oportunidades que as pessoas acessam.

Exemplos estão entre os elementos constitutivos do desenvolvimento e a contribuição indireta dos mesmos na agregação de valores no progresso econômico; na relação entre renda per capita e "a liberdade para ter uma vida longa e viver bem” (Sen, 2000, p.20); a contribuição do 
mecanismo de mercado e o "reconhecimento da importância direta da liberdade de troca - de palavras, bens, presentes" (Sen, 2000, p.21), assim como da privação de liberdade econômica de participar do mercado de trabalho.

O desenvolvimento deve também ser visto "como um processo integrado de expansão de liberdades substanciais interligadas" (Sen, 2000, p.23), de forma que seja sustentado pela razão, e não pela imposição econômica. Nesse processo, as instituições devem favorecer a ligação de cinco liberdades instrumentais: "1. liberdades políticas; 2. facilidades econômicas; 3. oportunidades sociais; 4.garantias de transparência e 5. segurança protetora" (Sen, p.28) na forma de políticas públicas.

A efetivação das liberdades fortalece umas às outras, permitindo com que os indivíduos possam organizar seu próprio destino e se solidarizar com os outros, ou seja, tenham liberdade de escolha. ${ }^{12}$

O ponto de partida do questionamento de Sen é a relação entre renda e realizações, entre mercadorias e capacidades. Segundo o autor, tal relação funciona como meio de incrementar as liberdades para organizar o tipo de vida que temos razão para valorizar. Daí, que o crescimento econômico "tem de estar relacionado sobretudo com a melhora da vida que levamos e das liberdades que desfrutamos" (Sen, 2000, p.29). ${ }^{13}$

No mundo, porém, milhões de pessoas são vitimizadas por privações de liberdade diversas, sobretudo por privações políticas e dos direitos civis básicos, sem que isso resulte na ausência de desenvolvimento econômico. ${ }^{14} \mathrm{E}$, embora a segurança econômica possa relacionar-se com a ausência de direitos e liberdades democráticas, "a liberdade política e as liberdades civis são importantes por si mesmas, de um modo direto" (Sen, 2000, pp. 30-31). Daí, que não se justifica optar por um ou outro argumento dos seus efeitos sobre a economia. Sua importância constitutiva é equiparável à importância instrumental.

Nessa concepção, tal visão de liberdade "envolve processos que permitem a liberdade de ações e decisões como oportunidades reais que as pessoas têm, dadas as suas circunstâncias pessoais e sociais" (Sen, 2000, p.31).

A relação que se estabelece entre a expansão das capacidades das pessoas e as políticas públicas é de mão dupla nessa visão de desenvolvimento. A liberdade, para Sen, é "a base da avaliação de êxito e fracasso, mas também um determinante principal da iniciativa individual e da eficácia social" (Sen, 2000, p.33), ou do "aspecto da condição de agente" do indivíduo (não o que age em nome de outro, mas o que age "como membro do público e como participante de ações econômicas, sociais e políticas" - Sen, 2000, p.33). Isso implica repensar a noção de público-alvo das políticas públicas, definida desde concepções dos responsáveis pelas políticas, assim como a associação entre a atuação dos governos, o processo de fiscalização e rejeição democráticas.

Deve-se, assim, admitir que há implicações recíprocas entre privações de renda e de capacidades, mas que as primeiras não esgotam as explicações das segundas. A pobreza deve ser vista "como uma privação de capacidades básicas, e não apenas baixa renda" (Sen, 2000, p.35). O exemplo de desemprego é interessante, pois evidencia que ele "é também uma fonte de efeitos debilitadores muito abrangentes sobre a liberdade, a iniciativa e as habilidades dos indivíduos" (Sen, 2000, p.35). As associações entre renda e mortalidade são outros exemplos desenvolvidos pelo autor.

Nesse enfoque, a relação entre liberdade (apesar do seu grau de abrangência) e capacidades aproxima-se da preocupação com a qualidade de vida, que possui um retrospecto desde Aristóteles (florescimento e capacidade) e Adam Smith (necessidades e condições de vida). Essas referências foram inclusive motivações da origem da economia, que tiveram desdobramentos como em William Petty (séc. XVII), ao se preocupar "com a 'segurança comum' e a 'felicidade particular de cada homem" (Idem, p. 40), numa avaliação das condições de vida das pessoas.

Um aspecto importante da análise de Sen é sobre o papel do mecanismo de mercado. $\mathrm{O}$ argumento principal do autor supera a idéia de que os mercados promovem a expansão da renda, da riqueza e das oportunidades econômicas, em proveito do argumento de que a liberdade fundamental e anterior é a de que as pessoas têm o direito de fazer transações e trocas, direito que, negado, leva a perdas sociais. ${ }^{15}$

Busca recuperar, com tal argumento, o fato de que o liberalismo teria, em sua base, referências mais amplas que os princípios econômicos determinantes do discurso e das práticas atualmente hegemônicas. A passagem do trabalho adscritício e do forçado para o trabalho livre é, nesse sentido, importante, pois incorpora uma mudança de valorações aí envolvidas. Tema que se atualiza com o problema do trabalho infantil e dos trabalhos forçados a que são submetidos milhares de sujeitos, em sociedades periféricas, recolocando a questão da liberdade de escolha. Trata-se, aqui, da permanência de modelos de trabalho adscritício que criam obstáculos ao desenvolvimento dos valores fundantes da formação humana, a saber: educação e cultura.

Assim, o autor chega ao cerne de sua discussão: a da avaliação dos valores e do processo de valoração.

a liberdade (...) reside precisamente na oportunidade que ela dá aos cidadãos de debater sobre valores na escolha das prioridades e de participar da seleção desses valores (...). A liberdade individual é essencialmente um produto social (Sen, 2000, p.46),

assim como a participação, que deve ser referida em um 
manancial de autoridade e legitimidade, em última instância, processualmente coletivo.

O desenvolvimento, portanto, é um projeto coletiva e livremente escolhido.

Em Touraine (2000), o que explica as novas possibilidades de sociabilidade é a combinação que se possa produzir de novas estratégias de solidariedade, frente à exclusão.

Para o autor, na medida em que a humanidade vive sobre as ruínas do marxismo-leninismo e da sociedade burguesa, "sem a morte da sociedade e do ego, a procura e a defesa do sujeito não teriam sentido" (Touraine, 2000, p.71). E denuncia de modo incisivo: "o sujeito se acha tão ameaçado no mundo de hoje, pela sociedade de consumo que nos manipula ou pela busca de um prazer que nos aprisiona em nossas paixões, como o era no passado pela submissão à lei de Deus ou da sociedade" (Touraine, 2000, p.70). Para ele, o sujeito é a procura pelo próprio indiví-duo, "das condições que lhe permitem ser o ator da sua própria história", configurando dois processos, ou seja, 1. "o desejo do indivíduo de ser um ator"; 2. "o desejo de individualização".

No processo do indivíduo em ser um ator, o sujeito não é uma simples forma da razão, mas "é liberdade, libertação e negação". No processo da vontade da individuação constitui-se a subjetivação quando "o indivíduo se define novamente por aquilo que faz, por aquilo que valoriza e pelas relações sociais nas quais se acha assim engajado" (Touraine, 2000, p.76). Dessa forma, para Touraine, o sujeito resulta da reconstrução e recuperação da unidade do indivíduo - seu desejo de ser ator, seu esforço de subjetivação - como unidade consciente e com uma identidade. Permanecendo o indivíduo na dualidade, ele aceita os apelos do mercado e cai no consumismo desenfreado e acrítico. Não tendo essa possibilidade, sucumbe no mundo das drogas, da violência e dos excluídos do sistema. Os sujeitos excluídos do sistema encontram suas saídas na construção comunitária, nas redes solidárias e na solidariedade.

A temática do sujeito necessita ser recheada de conteúdo social e político que ultrapasse as demandas do Ego e atenda às exigências da liberdade, da igualdade e da justiça. Não são meras especulações cognitivas, mas buscas concretas para uma melhor organização da sociedade, tornando-a mais justa. Para tanto, Touraine sugere que deve haver avanços em três níveis: 1. "o conflito aberto - exigência pessoal de liberdade quanto ao poder dos sistemas"; 2. "o debate pelo qual se definem as condições institucionais de respeito e encorajamento da liberdade de cada um"; e 3. "a formação geral da equiidade, mas, sobretudo, mais concretamente, das condições da integração social e de uma mudança sustentável"'(Touraine, 2000, p.87). Para ele, na seqüência das etapas, a análise oscila "do sujeito pessoal para a comunicação entre os sujeitos e depois para as instituições, à liberdade do sujeito pessoal numa análise sempre mais cognitiva das re- gras de funcionamento da sociedade" (Touraine, 2000, p.87).

Nisso, o autor enquadra sua trajetória intelectual de compreensão e interpretação do sujeito, desde a análise do movimento operário até as recentes posições em relação aos movimentos sociais. Afirma que o lugar central dado à idéia de sujeito deve ser identificado em cada momento histórico, quando talvez se localize a "imagem de uma sociedade ideal ou historicamente necessária", porque "muitos falam em nome da liberdade e da justiça - e sobretudo da igualdade"(Touraine, 2000, p.91). Então, ele sinaliza que prevalece a "exigência de cada indivíduo de se tornar um ator da própria história, um ser humano à procura da felicidade e um cidadão que procura, tanto para os outros como para a sua própria liberdade, a proteção da lei" (Idem, p. 94), num mundo dividido entre o das identidades comunitárias e o da economia mundializada.

E os sujeitos coletivos? São construídos e constituídos pelos diferentes movimentos sociais, sindicatos e organizações.

É na práxis dos movimentos sociais que se burilam os sujeitos sociais, os sujeitos culturais que se constituem em sujeitos políticos. Eles constroem saberes, valores, cultura. Os processos educativos desses sujeitos brotam das tensões, dos conflitos, das contradições da ordem social vigente.

\section{Considerações Finais}

Quero finalizar, com base nas discussões anteriores, com a idéia de que o jogo das relações entre exclusão e controle social, de um lado, e liberdade e autonomia dos sujeitos, de outro, passa, na atualidade, pela combinação dos fatores que definem os novos condicionamentos sociais. Os elementos desses novos condicionamentos são: a ideologia da fragmentação da experiência social, a nova racionalidade instrumental em torno da apropriação dos fundos públicos, as privações sociais definidas por Sen e a manipulação e busca do prazer configuradas na sociedade de consumo, ${ }^{16}$ entre outros.

Esses elementos implicam que o campo de ações dos sujeitos contemporâneos é plural, o que inclui mesmo a sociabilidade configurada em condições de privação social, como na pobreza ou na exclusão. Essa condição nos coloca uma constante necessidade de refletir e redefinir ações sociais na esfera acadêmica ou governamental, atentando aos critérios de comunidade (ou aos padrões de sociabilidade territorialmente definidos) e institucionalidade.

Isso porque nós ainda trabalhamos com a concepção ideológica da pobreza homogênea, na forma de uma "pobreza integrada" (Paugam, 1999, p.97), porque comunitária e solidária, que está em vias de extinção.

Embora necessidades de bases territoriais possam ainda ser importantes, elas já não possuem mais a mesma 
potência de integração dos movimentos sociais, como projeto de sociedade. A multidimensionalidade dos processos de exclusão extrapola os limites locais de reconhecimento das condições de privação social vivenciadas pelos sujeitos, fragmentando as lutas sociais em processos reivindicatórios específicos, que necessitam ser ressignificados por novos sentidos globais (Bauman, 2005; Sarlo, 2005).

As políticas sociais contemporâneas priorizam, equivocadamente, atingir os excluídos que estão no limite das privações através de programas focalizados que sustentam rótulos de "inclusão social". Porém, o problema da concepção de "exclusão social" deixa de ser sua configuração como modelo de redução da condição do sujeito quando definimos políticas de "inclusão social", uma vez que toda forma de inclusão realiza-se institucionalmente. Isso implica aceitar a idéia de que "as instituições não podem se dirigir aos sujeitos sem tratá-los como objetos. ${ }^{17}$ As instituições não podem ser âmbito de reconhecimento entre sujeitos, porque tal reconhecimento rompe, enquanto ocorre, a lógica institucional" (Hinkelammert, 1988, p.254).

Enquanto no Estado de Bem-Estar Social pressupunhase a produção da maior quantidade possível de informações sobre os sujeitos, no que residia o poder de controle do Estado sobre os sujeitos, nas relações que configuram a concepção de "exclusão social", essas informações são inexistentes, e nem oferecem mais a mesma importância que possuíam antes.

Hoje, contam muito mais as regras que se impõem aos excluídos para que participem - ou ao menos se sintam participantes - dos jogos de sociabilidade.

\section{Notas}

1. Da perspectiva do Estado totalizante, Marcuse afirma que se trata de "uma coordenação técnico-econômica não terrorista que opera através da manipulação das necessidades por interesses adquiridos" (1967, pp.25-25), que "se afirma através dos seus poderes sobre o processo mecânico e sôbre a organização técnica do aparato" (p.25) produtivo. Ao mesmo tempo, esse Estado busca produzir uma gama muita extensa de informações sobre as necessidades dos indivíduos, que o capacita a controlar melhor os mesmos.

2. Essa idéia se aproxima da concepção de "situação de classe", em Weber (s/d, p.212), expressa "mais sucintamente como a oportunidade típica de uma oferta de bens, de condições de vida exteriores e experiências pessoais de vida, e na medida em que essa oportunidade é determinada pelo volume e tipo de poder, ou falta deles, de dispor de bens ou habilidades em benefício de renda de uma determinada ordem econômica. A palavra 'classe' refere-se a qualquer grupo de pessoas que se encontrem na mesma situação de classe". O destino dos sujeitos de uma dada classe social seria "determinado pela oportunidade de usar, em proveito próprio, bens e serviços no mercado" (p.214).

3. Santos (1997,p.16) apropria-se da idéia formulada por F. Perroux, segundo a qual uma estrutura "se define por uma 'rede de relações, uma série de proporções entre fluxos e estoques de unidades elementares e de combinações objetivamente significativas dessas unidades"”, para argumentar que "as estruturas [...] são formadas de elementos homólogos e de elementos nãoho-mólogos. Entre as primeiras, estão as estruturas demográficas, econômicas, financeiras, istoé, estruturas da mesma classe e que, de um ponto de vista analítico, podem-se considerar como estruturas simples.
As estruturas não homólogas, isto é, formadas de diferentes classes, interagem para formar estruturas complexas. [...] A realidade social, tanto quanto o espaço, resultam da interação entre todas essas estruturas" (pp.16-17).

4. Lembre-se da distinção que Habermas (1990) elabora entre mundo vivido e mundo sistêmico. No primeiro, marcado pela reprodução simbólica (interação), o autor refere-se à experiência comum a todos os indivíduos "atores", na qual se reflete o óbvio e o questionamento do feito das certezas são possíveis a partir da ação comunicativa. Já no segundo, é onde se realiza a razão instrumental, objetivada nos subsistemas econômico e político, que desenvolvem mecanismos auto-reguladores, o dinheiro (capital) e o poder (burocracia), e que permite a "integração sistêmica". Essa distinção é também discutida em Freitag (1990). Agradeço à colega Cecília Pescatore Alves a indicação dessas referências.

5. Perceba-se que, para cada uma dessas formas gerais pode-se constatar também formas distintas de efetivação do controle social.

6. Ou seja, as classes trabalhadoras foram substituídas pelos sindicatos e outras organizações classistas, a burguesia e sua expressão capitalizada, na forma do empresariado, foram substituídas pelo mercado, e o Estado foi substituído pela competição partidária na disputa pelos governos.

7. No livro "A paz perpétua e outros opúsculos", Kant escreve que o Iluminismo "é a saída do homem da sua menoridade de que ele próprio é culpado" (1992, p.11). Tal saída seria condicionada pela liberdade que, para ele, caracteriza-se pelo uso público da razão em todos os elementos. Como Kant não vê tal uso ser exercido regularmente, sugere que a menoridade do homem manifesta-se, assim, pela "falta de decisão e de coragem em se servir de si mesmo sem a orientação de outrem" (Idem).

O que Kant nos diz quando escreve isso? Ele próprio responde: a preguiça e a covardia nos impedem de pensar e exercer o uso público da razão. Deixamos esse exercício para outros sujeitos, dispostos a isso, e nos acomodamos na menoridade, tornando-a natural. Nessa menoridade, mais que discutir as contradições, passamos a raciocinar com preceitos e fórmulas, de maneira mecânica, perpetuando a menoridade.

Uma das heranças da filosofia kantiana seria essa: quem pensa e exercita sua razão não alcança a paz, porque não se acomoda. Mas é difícil sair da menoridade, segundo Kant, porque há restrições à liberdade por toda parte. O sujeito é impelido, por essas restrições, a utilizar sua razão privadamente. Nessa situação, a liberdade é sempre potencial, mas nunca plena, porque no exercício privado da razão suponho que os outros sujeitos são passivos.

Logicamente, essa concepção de sujeito, centrada no individualismo racional que tanto influenciou o Iluminismo, sofreu transformações profundas no desenvolvimento das teorias sociológicas e do pensamento social na sociedade ocidental. Stuart Hall (2005) elabora uma síntese consistente dessas mudanças. Entretanto, pretendo reforçar aqui não o próprio individualismo racional, mas sim, o caráter conflitual da relação entre o uso público da razão e as restrições a esse uso (restrições à liberdade), que impregna a origem dessa categoria, para evidenciar que essa cisão se manteve nas transformações discursivas, até a atualidade, mesmo naquelas que consideram as sociedades atuais "atravessadas por diferentes divisões e antagonismos sociais que produzem uma variedade de diferentes 'posições de sujeio' - isto é, identidades - para os indivíduos" (Hall, 2005, p.17).

8. Esse último aspecto está considerado no texto de Hilary Silver, na mesma coletânea, intitulado Reconceptualizing social 
disadvantage: three paradigms of social exclusion, onde o autor identifica vinte e cinco categorias de indivíduos caracterizados como excluídos, nos estudos das décadas de 1980 e 90, na Europa.

9. Jung Mo Sung utiliza o conceito de sujeiticidade em substituição ao de subjetividade, para aproximar a sua discussão ao pensamento de Hinkelanmert (1988). Aproprio-me do conceito, aqui, entendendo-o como equivalente ao conceito de formação do sujeito, que se desenvolve no ocidente desde o projeto iluminista, passando pela concepção de sujeito sociológico (Hall, 2005): é um processo incessante pelo qual o ser humano usa da razão para estabelecer mediações em suas ações e relações sociais. $\mathrm{O}$ componente mais ativo de tal processo é a condição de liberdade de escolha, na qual o ser humano é capaz de realizar opções, frente a outros seres humanos, na esfera pública, assumindo um projeto de sociedade e atuando em prol do mesmo.

10. Ewald (1995), ao apresentar o estudo de Rosanvallon, afirma que o Estado-providência clássico é ineficaz no combate à exclusão e que ele funciona "segundo uma lógica da amplificação das injustiças pelo engendramento de uma sociedade dual. [...] o Estado providência clássico [...] não pode mais pretender ser um princípio do contrato social, ligar a sociedade a ela mesma, na medida que ele associa apenas uma fração da sociedade". Segundo o autor, "a percepção dos riscos sociais, como sua realidade, mudou”. Os indivíduos reconhecem que o principal risco não é mais o de perderem rendimentos em casos de infortúnio, mas o desemprego e a exclusão que segue dele; reconhecem o princípio de sua organização não mais na defesa da condição salarial, segundo uma lógica dos direitos e das liberdades, mas na procura de uma garantia do trabalho; reconhecem que o risco da exclusão não atinge somente "populações identificadas pelos status sócioeconômicos largos, como o assalariado, mas a indivíduos em função de histórias e de percursos sempre singulares".

11. Os modelos dos Programas de Renda Mínima, no Brasil, com as especificações das obrigações dos assistidos, foram analisados por Sposati (1997). Na mesma coletânea organizada pela autora, inclui-se um artigo onde discuto os limites de tais obrigações, frente às imposições ditadas pelo mercado.

12. A liberdade de escolha é um dos aspectos centrais na constituição dos novos modelos de solidariedade, como entre os sujeitos que praticam trabalhos voluntários, como mostra um estudo recente de Souza e Feitosa (2003).

13. Concepção que se aproxima da distinção que Perroux (1967) elabora, na década de 70, entre crescimento e desenvolvimento social.

14. E vice-versa. Ver a esse respeito o artigo de Reis e Cheibub (1993).

15. Sen elabora uma distinção entre "resultados de culminância" e "resultados abrangentes" no discurso econômico (baseada na ênfase sobre resultados finais e processos, respectivamente, na análise do cálculo do desenvolvimento), para mostrar que a predominância dos primeiros levou à passagem da economia como liberdade para a economia pró-mercado, de utilidade.

16. Como essa sociedade de consumo estrutura-se sobre os processos de produção e circulação de mercadorias, na economia globalizada, penso que é nesse escopo de relações mais amplas que se inserem as formas de controle operadas pela produção de informações em rede, como expõe M. Castells (2003). Segundo o autor, esse modelo de organização social expropria do sujeito o controle sobre suas próprias decisões e sua capacidade de planejar o futuro.

17. Mesmo em concepções como a de Berger e Berger (1974), de orientação construtivista, a lógica institucional refere-se a uma dinâmica socializadora, portanto, condicionadora. Daí, que as características da instituição descritas pelos autores sejam: exterioridade, objetividade, coercitividade, autoridade moral e historicidade.

\section{Referências}

Arrighi, G. (1997). A ilusão do desenvolvimento (3a . ed.). Petrópolis, RJ: Vozes.

Atkinson, Rob (1998). Combatendo a exclusão social urbana: o papel da participação comunitária na regeneração das cidades européias. Cadernos IPPUR/UFRJ, XII(1), 107-128.

Badiou, A. (1994). Verdade e sujeito. Estudos Avançados, 8(21), 177-184.

Bauman, Z. (2005). Identidade. Rio de Janeiro: Jorge Zahar.

Berger, B. \& Berger, P. (1977). O que é uma instituição social? Em J.S. Martins \& M.M. Foracchi (Eds.), Sociologia e sociedade: leituras de introdução à sociologia (pp. 193-199). São Paulo: LTC.

Bertrand, M. (1989). O homem clivado - a crença e o imaginário. Em P. Silveira \& B. Doray (Eds.), Elementos para uma teoria marxista da subjetividade (pp. 15-40). São Paulo: Vértice.

Bourdieu, P. (1997). A miséria do mundo. Petrópolis, RJ: Vozes.

Castells, M. (2003). A galáxia da internet: reflexões sobre a internet, os negócios e a sociedade. Rio de Janeiro: Jorge Zahar.

Castel, R. (1999). As metamorfoses da questão social: uma crônica do salário (2a . ed.). Petrópolis, RJ: Vozes.

Dobb, M. (1983). A evolução do capitalismo. Rio de Janeiro: Jorge Zahar.

Dubet, F. (1996). Curso sobre exclusão social. (Transcrição de curso realizado pelo autor na USP), de 9 a 13 de setembro, $114 \mathrm{p}$.

Dupas, G. (1999). Economia global e exclusão social: pobreza, desemprego, estado e o futuro do capitalismo ( $2^{\mathrm{a}}$. ed.). Rio de Janeiro: Paz \& Terra.

Ewald, F. (1995). Nacionalizar o social. Em P. Rosanvallon (Ed.), La nouvelle question sociale: repenser l'etat-providence. Paris: Seuil.

Foracchi, M.M. (1982). A participação social dos excluídos. São Paulo: Hucitec.

Freitag, B. (1990). A teoria crítica: ontem e hoje (3 ${ }^{\text {a }}$ ed.). São Paulo: Brasiliense.

Giddens, A. (1991). As conseqüências da modernidade (2a . ed.). São Paulo: Ed. UNESP.

Habermas, J. (1990). O discurso filosófico da modernidade. Lisboa: Publicações Dom Quixote.

Hall, S. (2005). A identidade cultural na pós-modernidade (10ª. ed.). Rio de Janeiro: DP \& A.

Harvey, D. (1992). Condição pós moderna. uma pesquisa sobre as origens da mudança cultural. São Paulo: Loyola.

Hinkelammert, F. (1988). A crítica da razão utópica. São Paulo: Paulinas.

Hobsbawm, E.J. (1988). Mundos do trabalho (2a . ed.). São Paulo: Paz e Terra.

Honneth, A. (1992). Integrity and disrespect: principles of a conception of morality based on the theory of recognition. Political Theory, 20(2), 187-201.

Kant, I. (1992). A paz perpétua e outros opúsculos. Lisboa: Edições 70.

Kliksberg, B. (1993). Pobreza, un tema impostergable - nuevas respuestas a nivel mundial. México: Fondo de Cultura Economica. 
Kowarick, L. (1979). A espoliação urbana. Rio de Janeiro: Paz e Terra.

Kowarick, L. (1991). Cidadão privado e subcidadão público. São Paulo em Perspectiva, 5(2), 2-8.

Kowarick, L. (Ed.) (1994). As lutas sociais e a cidade (2a . ed.). Rio de Janeiro: Paz \& Terra.

Lefebvre, H. (1977). A "práxis”: a relação social como processo. Em J.S. Martins \& M.M. Foracchi (Eds.), Sociologia e sociedade: leituras de introdução à sociologia. (pp. 175-192). São Paulo: LTC.

Lévi-Strauss, C. (1976). Antropologia estrutural. Rio de Janeiro: Tempo Brasileiro.

Lopes, J.R. (2001). Urbanidade e cidadania: as modulações do urbano e o direito à cidade. Ciências Sociais Unisinos, 37(158), 67-92.

Lopes, J.R. (2002). Pobreza, subjetividade e cidadania. Serviço Social \& Sociedade, 70, 160-172. São Paulo: Cortez.

Lopes, J.R. (2004). “Terceiro setor”, a organização das políticas sociais e a nova esfera pública. São Paulo em Perspectiva, 18(3), 57-66.

Marcuse, H. (1967). Ideologia da sociedade industrial. Rio de Janeiro: Zahar.

Martins, J. S. (1997). Exclusão social e a nova desigualdade. São Paulo: Paulus.

Marx, K. (1984). O capital. crítica da economia política. São Paulo: Difel.

Nascimento, E.P. (1994). Hipóteses sobre a nova exclusão social. Dos excluídos necessários aos excluídos desnecessários. Cadernos CRH, 21, 29-47.

Negri, T. (2002). O poder constituinte: ensaio sobre as alternativas da modernidade. Rio de Janeiro: DP \& A.

Oliveira, F. (1988). O surgimento do anti-valor. Estudos CEBRAP, $22,8-28$.

Oliveira, F. (1998). Os direitos do anti-valor. Petrópolis, RJ: Vozes.

Oliveira, L. (1997). Os excluídos existem? Notas sobre a elaboração de um novo conceito. Revista Brasileira de Ciências Sociais, 12(33), 49-60.

Paugam, S. (1999). O conceito de desqualificação social. Em M.P.B. Veras (Ed.), Por uma sociologia da exclusão social: o debate com Serge Paugam (pp. 63-80). São Paulo: EDUC.

Pedlowski, M.A. (2001). O ressurgimento da sociedade civil e o lugar de suas organizações nos processos de democratização e desenvolvimento econômico. Ciências Sociais Unisinos, 37(159), 153-175.

Perroux, F. (1967). O desenvolvimento. Em O. Velho (Ed.), Sociologia do desenvolvimento . (pp. 17-26). Rio de Janeiro: Jorge Zahar.

Reis, E.P. \& Cheibub, Z.B. (1993). Pobreza, desigualdade e consolidação democrática. Dados - Revista de Ciências Sociais, 36(2), 233-259.

Rogers; Garry; Gore, C. \& Figueiredo, J. (Eds.) (1995). Social exclusion: rethoric, reality, responses. Genebra: International Institute for Labor Studies.

Rosanvallon, P. (1995). La nouvelle question sociale. repenserl'etatprovidence. Paris: Seuil.

Santos, B.S. (1995). Pela mão de alice: o social e o político na pósmodernidade. São Paulo: Cortez.
Santos, M. (1997). Espaço e método (4ª . ed.). São Paulo: Nobel. Santos, M. (1987). O espaço do cidadão. São Paulo: Nobel.

Sarlo, B. (2005). Tempo presente. notas sobre a mudança de uma cultura. Rio de Janeiro: José Olympio.

Sen, A. (2000). Desenvolvimento como liberdade. São Paulo: Cia das Letras.

Singer, P. (1996). Desemprego e exclusão social. São Paulo em Perspectiva, 10(1), 3-12.

Souza, J.O. \& Feitosa, S. (2003). Ação social voluntária: motivação e evasão. Cadernos CEDOPE, 19.

Souza, J. (2000). Uma teoria crítica do conhecimento. Lua Nova, $50,133-158$.

Sposati, A. (Ed.) (1996). Mapa da exclusão/inclusão social da cidade de São Paulo. São Paulo: Educ.

Sposati, A. (Ed) (1997). Renda mínima e crise mundial: saída ou agravamento? São Paulo: Cortez.

Sung, J.M. (2002). Sujeito e sociedades complexas: para repensar os horizontes utópicos. Petrópolis, RJ: Vozes.

Touraine, A. (1989). Os novos conflitos sociais: para evitar mal-entendidos. Lua Nova, 17, 5-18.

Touraine, A. (2000). Podremos vivir juntos? Iguales y diferentes ( $2^{\mathrm{a}}$. ed.). México: Fondo de Cultura Economica.

Veras, M.P.B. (Ed.) (1999). Por uma sociologia da exclusão social: o debate com Serge Paugam. São Paulo: Educ.

Wanderley, M.B. (1997). Refletindo sobre a noção de exclusão. Serviço Social \& Sociedade, 55, 74-83.

Wanderley, L.E.W. (1997a). A questão social no contexto da globalização: o caso latino-americano e o caribenho. Em L. Bógus, M.C.Yazbek, \& M.B. Wanderley (Eds.), Desigualdade e a questão social (pp. 49-160). São Paulo: Educ.

Weber, M. (s/d). Ensaios de sociologia. Rio de Janeiro: Jorge Zahar.

Zarth, P.A. et al. (Eds.) (1998). Os caminhos da exclusão social. Ijuí, RS: Unijuí.

José Rogério Lopes é Doutor em Ciências Sociais (PUC-SP), Professor Titular do PPG em

Ciências Sociais, Unisinos, RS. O endereço para correspondência com o autor é PPG

Ciências Sociais - Unisinos. Av. Unisinos, 950. São Leopoldo - RS, CEP 93022-000. jrlopes@unisinos.br

Dedicatória: para Cecília, Régis, André, Leandro e Pimenta, parceiros no NIPPC.

\section{"Exclusão social" e controle social: estratégias contemporâneas de redução da sujeiticidade}

José Rogério Lopes

Recebido: 27/06/2005

$1^{\text {a }}$ revisão: $15 / 02 / 2006$

$2^{\mathrm{a}}$ revisão: 07/05/2006

Aceite final: 10/05/2006 